ФГБОУ ВО «Байкальский государственный университет», ул. Ленина, д. 11, Иркутск, 664003, Россия

e-mail: econo2017@yandex.ru

\begin{abstract}
Аннотация
Рассматривается проблема создания эффективной системы оплаты труда в сфере здравоохранения.

Система оплаты труда в государственных (муниципальных) учреждениях здравоохранения была дважды реформирована. В настоящее время начинается новый этап, обусловленный как нерешенными вопросами (отсутствие единых подходов к регулированию оплаты труда, высокая меж- и внутрирегиональная дифференциация), так и новыми вызовами (последствиями пандемии 2020 г.).

Цель исследования: рассмотреть основные этапы реформирования системы оплаты труда в учреждениях здравоохранения в Российской Федерации; охарактеризовать содержание реформы, достигнутые результаты и существующие проблемы, дать оценку.

Результаты исследования:

1. Проведен анализ проблем, связанных с достижением целевых показателей по заработной плате медицинского персонала, раскрыты причины.

2. Выявлены факторы, снижающие эффективность применяемой системы оплаты труда: экономические (уровень финансирования учреждений), управленческие (высокая степень самостоятельности руководителей учреждений в распоряжении средствами) и организационные (отсутствие прозрачного механизма оценки и стимулирования работников).

3. Предложено: скорректировать целевые показатели по заработной плате медицинского персонала в соответствии со средним заработком работников системообразующих предприятий региона; не включать в состав заработной платы не ниже минимального размера оплаты труда (МРОТ) выплаты стимулирующего характера.

В статье приводятся итоги федерального статистического наблюдения в сфере оплаты труда работников здравоохранения в 2013-2019 гг., указана нормативноправовая база, методика расчета ключевых показателей, проведен обзор новейших изменений в законодательстве.
\end{abstract}

Ключевые слова: реформы здравоохранения, система оплаты труда, целевые показатели, медицинский персонал, средняя заработная плата, эффективный контракт, учреждения здравоохранения, системообразующие предприятия.

Информация для цитирования: Соболева Е.А. О реформировании системы оплаты труда в здравоохранении: достижения, проблемы, коррективы // Научный результат. Экономические исследования. 2020. Т. 6. № 4. С. 80-90. DOI: 10.18413/2409-1634-2020-6-4-0-9 


\title{
Elizabeth A. Soboleva $\mid$ On reforming the remuneration system in health care: achievements, challenges, adjustments
}

\author{
Baikal State University, 11 Lenin St., Irkutsk, 664003, Russia, \\ e-mail: econo2017@yandex.ru
}

\begin{abstract}
The article studies the problem of the effective remuneration system development in healthcare.

The remuneration system of the state (municipal) health care institutions has been reformed twice. Today, a new stage is being started, which is caused by a number of unsettled questions (such as a lack of unified approaches to salary regulation, large interand intra-regional differentiation) and new challenges (pandemic after-effects).

Purpose: to consider main stages of the remuneration system reforming in health care institutions of the Russian Federation; to characterize the reform content, achieved results and current problems, to give an opinion.

Results:

1. The author analyzes the problems associated with achievement of the target indicators on medical personnel salaries, and provides an explanation.

2. The author reveals the factors reducing efficiency of the existing remuneration system: economic (funding level of the institutions), managerial (high degree of autonomy of heads of the institutions in administering funds) and organizational (absence of transparent techniques of personnel assessment and motivation).

3. The author suggests correcting the target indicators on medical personnel salaries in line with the average salaries of strategic enterprises employees; not to include the stimulating payments in the amount of the minimal salary.

The article contains data of the Federal statistical observation of the remuneration in healthcare for the 2013-2019 years; specifies calculation methods of basic indicators; observes the relevant legislative acts, including the newest ones.
\end{abstract}

Key words: public health reform; remuneration system; target indicators; medical personnel; average salary; effective contract; health care institutions; strategic enterprises.

Information for citation: Soboleva E. A. "On reforming the remuneration system in health care: achievements, challenges, adjustments", Research Result. Economic Research, 6(4), 80-90, DOI: 10.18413/2409-1634-2020-6-4-0-9

\section{Введение}

В кризисные 90-е гг. словосочетание «бюджетная сфера» и все, что с этим связано, приобрело резко негативный оттенок и ассоциировалось с низкими зарплатами, непрестижностью профессий врача и учителя.

Со временем ситуация изменилась. Работать в бюджетном секторе стремятся многие специалисты, среди которых и вы- пускники престижных образовательных программ [Abuzyarova, Belousova, Krayushkina, Lonshcikova, Nikiforova, Chichkanov, 2019]. Как минимум, это подразумевает социальные гарантии (официальное трудоустройство, положенное число дней отпуска в году, оплачиваемый больничный и т. д.) и своевременную заработную плату (пенсионные отчисления в полном объеме, возможность взять кредит и др.). 
Однако в сфере оплаты труда до сих пор сохраняется ряд серьезных проблем, которые не были устранены (или даже возникли) в ходе реформ. Прежде чем перейти к следующему этапу преобразований, начало которому уже положено, следует подвести промежуточные итоги. Данное исследование посвящено результатам реформирования системы оплаты труда в (государственном) здравоохранении.

Материалы и методы исследования. Источники информации: нормативноправовые акты Российской Федерации, официальные документы Минздрава и Минтруда России, статистические данные Росстата, результаты независимых исследований, публикации в средствах массовой информации, научные статьи.

Используются общелогические (анализ, аналогия, индукция) и общенаучные методы (систематизация информации, графическая и табличная интерпретация).

\section{Основная часть}

С 1992 г. в Российской Федерации (далее - РФ) действовала единая тарифная система оплаты труда (ЕТС), которая предусматривала 18 разрядов для всех работников бюджетной сферы. Унифицированный и не гибкий подход к регулированию оплаты труда породил массу исключений: за время действия ЕТС вышло более тысячи (ведомственных) нормативноправовых актов [Семеко, 2010].

В 2008 г. началась «зарплатная реформа». Новая система оплаты труда (далее - НСОТ) установлена Постановлением Правительства РФ от 5.08.2008 № 583 в федеральных учреждениях, в соответствии с которым государственные (муниципальные) учреждения субъектов РФ также перешли на НСОТ.

Введенная в целях повышения мотивации работников и эффективности их деятельности, НСОТ существенно расширила самостоятельность учреждений при формировании штата и распределении фонда оплаты труда (далее - ФОТ).
Структура заработной платы (далее зарплаты): оклад (на ставку), выплаты компенсационного и стимулирующего характера.

Оклады устанавливаются на базе профессиональных квалификационных групп (далее - ПКГ). ПКГ должностей медицинских и фармацевтических работников утверждены Приказом Минздравсоцразвития России от 6.08.2007 № 526.

Перечни видов выплат компенсационного и стимулирующего характера утверждены Приказами Минздравсоцразвития России от 29.12.2007 № 822 и от 29.12.2007 № 818 .

Введение НСОТ, в целом, положительно повлияло на динамику зарплаты ра-

ботников здравоохранения и социальной сферы, которая к 2011 г. выросла в 1,8 раза. блемы:

Но были выявлены следующие про-

- отсутствие конкретных измеримых параметров качества и интенсивности труда;

- большое различие в размерах зарплат руководителей и работников;

- низкий размер гарантированной части зарплаты;

- неконкурентоспособный размер зарплаты на региональном рынке труда.

В связи с этим, а также с совершенствованием правового положения государственных (муниципальных) учреждений (согласно Федеральному закону РФ от 08.05.2010 № 83-Ф3), в 2012 г. начался следующий этап «зарплатной реформы».

Программа поэтапного совершенствования системы оплаты труда в государственных (муниципальных) учреждениях на 2012-2018 гг., утвержденная Распоряжением Правительства РФ от 26.11.2012 № 2190-р, предусматривает:

1. Совершенствование нормативноправовой базы:

- установление базовых окладов, актуализацию ПКГ и требований к работникам, типовых норм труда, содержания трудовых функций; 
- разработку показателей эффективности деятельности учреждений, руководителей, работников; отмену неэффективных стимулирующих выплат.

2. Введение эффективного контракта: трудовой договор, в котором конкретизированы должностные обязанности работника, условия оплаты труда, меры социальной поддержки.

Условия оплаты труда включают: размер (должностного) оклада, ставку зарплаты за месяц или за норму труда, размеры и условия предоставления компенсационных и стимулирующих выплат.

3. Регламентацию оплаты труда руководителей учреждений:

- заключение трудового договора на принципах эффективного контракта;

- представление сведений о доходах, имуществе, обязательствах (в т. ч. супруга, несовершеннолетних детей);

- установление предельного соотношения средней зарплаты руководящего состава (руководителя, заместителей, главного бухгалтера) и работников учреждения: не более 6-кратного размера.

4. Достижение законодательно установленных целевых показателей по зарплате. Согласно Указу Президента РФ от 7.05.2012 № 597, к 2018 г. зарплата врачей должна быть повышена до $200 \%$ от средней зарплаты в регионе, а зарплата среднего и младшего медицинского персонала (далее медперсонала) повышена до 100\%.

Методические рекомендации по разработке показателей и критериев эффективности деятельности утверждены Приказом Минздрава России от 28.06.2013 № 421 .

С 2013 г. Российской трехсторонней комиссией по регулированию социальнотрудовых отношений (РТК) ежегодно принимаются Единые рекомендации по установлению (на федеральном, региональном и местном уровнях) систем оплаты труда работников государственных и муниципальных учреждений (далее - Единые рекомендации).
В каждом субъекте РФ утверждается Примерное положение об оплате труда работников учреждений здравоохранения, включающее минимальные размеры окладов и рекомендуемые размеры доплат, надбавок, премий.

На основании этого, в учреждениях здравоохранения принимаются свои Положения об оплате труда. Согласно ст. 144 Трудового кодекса РФ от 30.12.2001

№ 197-Ф3 (ред. от 09.11.2020), системы оплаты труда устанавливаются коллективными договорами, соглашениями, локальными нормативными актами.

С 2013 г. Росстат осуществляет мониторинг выполнения целевых показателей по зарплате медперсонала [Итоги федерального статистического наблюдения в сфере оплаты труда отдельных категорий работников социальной сферы и науки, 2013-2019].

Результаты достижения целевых показателей по зарплате медперсонала в РФ за январь-декабрь 2019 г. представлены в таблице. Итоги по РФ подсчитаны с учетом допустимого отклонения (в пределах $5 \%)$.

Общий порядок расчета средней зарплаты (или среднего заработка) установлен Постановлением Правительства РФ от 24.12.2007 № 922 (ред. от 10.12.2016), в целях мониторинга - Приказом Росстата от 14.04.2016 № 188 (ред. от 13.04.2017).

Сумма начисленной зарплаты включает: оплату труда по окладам, компенсационные выплаты (в т. ч. за совмещение, за расширение зон обслуживания, за сверхурочную работу, по сдельным расценкам и др.), стимулирующие выплаты (доплаты, надбавки, премии), а также единовременные выплаты, оплату питания и проживания, имеющую систематический характер. Т. е. все виды выплат (на все занимаемые ставки), относящиеся к оплате труда (до вычета НДФЛ и других удержаний). 
Таблица

Соотношение средней зарплаты медперсонала и среднемесячной начисленной зарплаты в регионе РФ за январь-декабрь 2019 г.

Table

Relation of the average salary of medical personnel to the average monthly accrued salary in the region of the Russian Federation in January-December of 2019

\begin{tabular}{|c|c|c|c|c|}
\hline \multicolumn{4}{|c|}{ Количество субъектов Российской Федерации, ед. } & $\begin{array}{l}\text { Итоги } \\
\text { по РФ }\end{array}$ \\
\hline \multicolumn{5}{|c|}{ Врачи (иные работники с высшим мед. или фарм. образованием): не менее 200\% } \\
\hline менее $195 \%$ & $\begin{array}{c}195- \\
199 \\
\%\end{array}$ & $\begin{array}{c}200- \\
210 \\
\%\end{array}$ & более $210 \%$ & \multirow{2}{*}{ 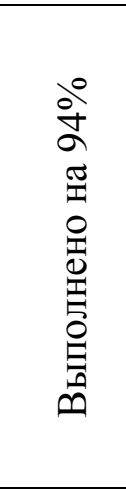 } \\
\hline \begin{tabular}{l}
\multicolumn{1}{c}{5} \\
(Мурманская, Ульяновская, Ма- \\
гаданская обл., Забайкальский \\
кр., Респ. Тыва)
\end{tabular} & 16 & 54 & $\begin{array}{l}10 \\
\text { (Курганская, Ленинградская, } \\
\text { Астраханская, Пензенская, } \\
\text { Челябинская, Новосибирская, } \\
\text { Сахалинская обл., Алтайский } \\
\text { кр., Респ. Дагестан, Чеченская } \\
\text { Респ.) }\end{array}$ & \\
\hline \multicolumn{5}{|c|}{ Средний медицинский (фарм.) персонал: не менее 100\% } \\
\hline менее $95 \%$ & $\begin{array}{l}95- \\
99 \%\end{array}$ & $\begin{array}{c}100 \\
110 \\
\%\end{array}$ & более $110 \%$ & \multirow[b]{2}{*}{ 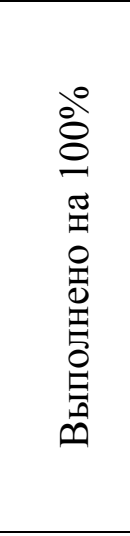 } \\
\hline e & 11 & 64 & $\begin{array}{l}10 \\
\text { (Московская, Калининград- } \\
\text { ская, Курганская, Челябин- } \\
\text { ская, Сахалинская обл., Став- } \\
\text { ропольский, Алтайский кр., } \\
\text { Респ. Дагестан, Кабардино- } \\
\text { Балкарская Респ., г.Санкт- } \\
\text { Петербург) }\end{array}$ & \\
\hline \multicolumn{5}{|c|}{$\begin{array}{c}\text { Младший медицинский (обеспечивающий предоставление мед. услуг) персонал: не менее } \\
100 \%\end{array}$} \\
\hline менее $95 \%$ & $\begin{array}{l}95- \\
99 \%\end{array}$ & $\begin{array}{c}100- \\
110 \\
\%\end{array}$ & более $110 \%$ & \multirow{2}{*}{ 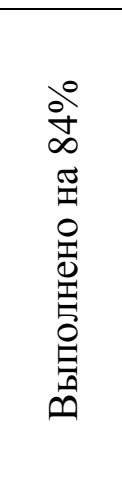 } \\
\hline $\begin{array}{l}14 \\
\text { (Мурманская, Ульяновская, Ке- } \\
\text { меровская, Магаданская обл., } \\
\text { Еврейская АО, Чукотский АО, } \\
\text { Пермский, Красноярский, Кам- } \\
\text { чатский, Приморский кр., Респ. } \\
\text { Коми, Адыгея, Тыва, Хакасия) }\end{array}$ & 34 & 36 & $\begin{array}{c}1 \\
\text { (Чеченская Респ.) }\end{array}$ & \\
\hline
\end{tabular}

С 2015 г. для расчета показателя среднемесячной начисленной зарплаты в регионе учитываются трудовые доходы как работников организаций, так и работников индивидуальных предпринимателей и физических лиц. Учет последних снижает показатель среднего заработка на 10 $12 \%$, что частично способствовало достижению целевых показателей [Лопатина, Ляшок, 2018]. 
Расчет средней зарплаты по каждой категории медперсонала производится на основании агрегирования (по всем учреждениям здравоохранения в субъекте РФ) данных о начисленной зарплате и количестве персонала (путем деления).

Известно, что достижение целевых показателей по зарплате медперсонала сопровождалось множеством проблем, рассмотрим основные из них:

1. Завышение размера официальной средней зарплаты.

Несовершенство метода расчета средней зарплаты (при котором учитываются как доходы рядовых сотрудников, так и руководящего состава), приводит к завышению данного показателя.

В 2017 г. реальный размер средней зарплаты врачей в России составил 46,8 тыс. руб. (до уплаты НДФЛ), что на 17\% ниже официальных данных [Результаты исследования зарплаты врачей государственных медучреждений России, 2017].

2. Повышение нагрузки на медперсонал.

Здесь несовершенство метода расчета (при котором размер средней зарплаты исчисляется не на ставку, а на физическое лицо) приводит к тому, что рост данного показателя происходит за счет роста нагрузки на одного работника.

В 2017 г., в среднем по России, врачи работали на 1,45 ставки (при максимальной нагрузке в 1,5 ставки). Согласно Постановлению Минтруда РФ от 30.06.2003

№ 41, продолжительность работы медицинских работников (далее - медработников) по совместительству не может превышать 1/2 месячной нормы рабочего времени.

Кроме официального совместительства, практикуется «совмещение должностей и расширение зоны обслуживания» [Совместное заявление профсоюза «Действие» и Гильдии защиты медицинских работников о зарплатах медиков, 2018]. Речь идет о случаях, когда дополнительные работы, ранее оплачивавшиеся сверх оклада, включаются в основные должностные обязанности работника [Подцероб, 2016].

3. Сокращение штата учреждений.

При неизменном числителе (ФОТ учреждения) уменьшение знаменателя (числа работников) приводит к увеличению получаемого значения (размера средней зарплаты).

В соответствии с этой нехитрой формулой, в ряде учреждений, несмотря на хроническую проблему кадрового дефицита в здравоохранении, проводились сокращения медработников.

Согласно Единым рекомендациям на 2020 г., утвержденным Решением РТК от 24.12.2019 протокол № 11, оценка результативности работы руководителя учреждения осуществляется с учетом показателя роста средней зарплаты работников в отчетном году.

В то же время, для учреждений с низкими доходами эта мера стала вынужденной, если не единственно возможной. Для того, чтобы обеспечить требуемый уровень зарплаты (или приблизиться к нему), более $80 \%$ своих доходов учреждения тратят на ФОТ [Синева, 2018].

Динамика численности врачей (иных работников с высшим медицинским или фармацевтическим образованием), среднего медицинского (фармацевтического) персонала и младшего медицинского (обеспечивающего предоставление медицинских услуг) персонала учреждений здравоохранения в РФ в 2013-2019 гг. представлена на рисунке.

Процессы сокращения персонала в отрасли подтверждаются статистическими данными (см. рисунок).

Кроме сокращения работников, проводилось также сокращение числа вакансий, тем самым, занижалась потребность в кадрах, саботировалась работа по устранению кадрового дефицита [Совместное заявление профсоюза «Действие» и Гильдии защиты медицинских работников, 2018]. 


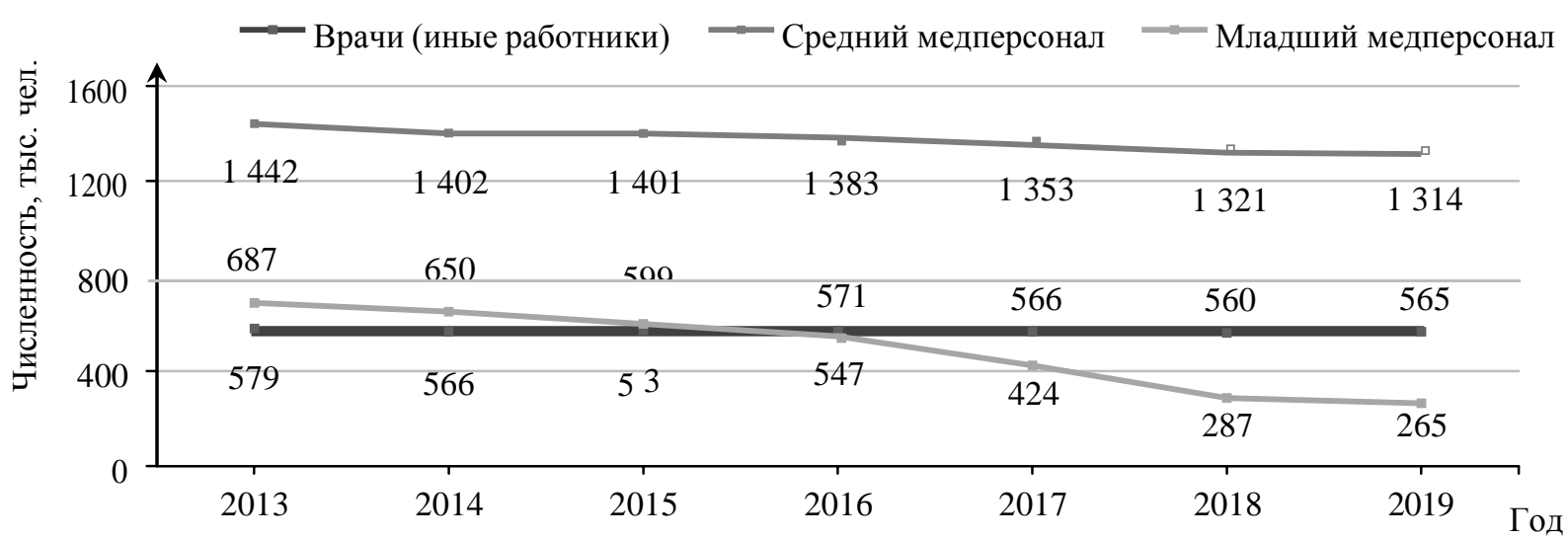

Рис. Численность медперсонала учреждений здравоохранения в России в 2013-2019 гг. Fig. Number of medical personnel in health care institutions in Russia in 2013-2019

4. Перевод медперсонала в другие категории.

Речь идет о проблеме экономии на зарплатах прочего (не медицинского) персонала учреждений здравоохранения. По этой причине младший медперсонал переводили в уборщики служебных помещений, с сохранением трудовых обязанностей санитара.

За период 2013-2019 гг. в РФ численность младшего медперсонала сократилась на 61\% или 422 тыс. чел. (см. рисунок).

Согласно Письму Минздрава России, сокращение должностей младшего медперсонала, замена должности «санитар» на «уборщик» в штатном расписании, перевод из санитаров в уборщики производятся учреждениями в соответствии с результатами аттестации работников и со сформированной структурой штата [О переводе младшего медицинского персонала на другие должности, 2018].

5. Управление доплатами и надбавками.

Данная «формула» используется при выполнении требований по повышению оклада: одно слагаемое (оклад) увеличивается, другие слагаемые (выплаты) уменьшаются, итоговая сумма (размер зарплаты) не изменяется.
Тем не менее, структура зарплаты тоже имеет значение. В соответствии с Едиными рекомендациями на 2020 г., задача повышения доли оклада (до 55\%) является одной из основных. Почему же так важно увеличить оклад?

Гарантированная часть зарплаты должна включать оклад и компенсационные выплаты (зависят от условий труда, полагаются за совмещение, сверхурочную работу и др.). Стимулирующие выплаты по определению относятся к мотивационной части.

Однако, в ряде регионов были выявлены факты неоплаты сверхурочной работы и работы по совместительству [Проверки Роструда выявили факты невыплат врачам сверхурочных в регионах, 2019]. В связи с этим, для того, чтобы минимизировать манипулирование доплатами, необходимо увеличить фиксированную часть зарплаты, т. е. оклад.

Сложности достижения целевых показателей в каждом российском регионе обусловлены множеством факторов: уровнем доходов бюджета и социальноэкономического развития, географическим положением, численностью населения и пр.

Немаловажную роль, по мнению экспертов, играет и уровень организации здравоохранения в регионе, который зави- 
сит от желания и способностей руководителей [Медицина в регионах: итоги-2019, 2019].

В силу способа расчета, зарплата каждого конкретного медработника может существенно отличаться от средней (не только по субъекту РФ, но и по учреждению).

По результатам анкетирования врачей-стоматологов, большинство из них (63\%) не компетентны в принципах формирования своей зарплаты [Бутова, Олесов, Зуев, Умарова, Жеребцов, Пешков, 2017]. Одной из главных проблем, по мнению авторов опроса, является недостаточное понимание медработниками принципов НСОТ и конкретных критериев оценки качества их труда, что делает применяемую систему малоэффективной.

С принятием Федерального закона от 09.11.2020 № 362-Ф3, наделяющего Правительство РФ полномочиями по формированию отраслевых систем оплаты труда, начался новый этап «зарплатной реформы» (в ходе которого будут учитываться и последствия пандемии 2020 г.).

С 2005 г. регулирование вопросов начисления зарплаты в государственных (муниципальных) учреждениях относится к полномочиям субъектов РФ (органов местного самоуправления), которые, во многом, передали их на уровень учреждений.

Проведенный анализ систем оплаты труда выявил как существенные межрегиональные различия, так и внутрирегиональную дифференциацию [Пояснительная записка к проекту федерального закона, 2020].

В сфере здравоохранения планируется разработать:

- требования к структуре зарплаты, единые перечни компенсационных и стимулирующих выплат и условия их назначения;

- нормативные акты, регулирующие оплату труда медработников, оказывающих первичную медико-санитарную помощь, скорую медицинскую помощь, мед- работников центральных районных и районных больниц.

Предполагается, что с 1 января 2021 г. будет применяться новая методика расчета минимального размера оплаты труда (далее - МРОТ) и прожиточного минимума [Госдума приняла в первом чтении проект о новой методике расчета МРОТ, 2020]. МРОТ будет рассчитываться как $42 \%$ от медианной зарплаты, прожиточный минимум - как 44,2\% от медианного среднедушевого дохода. В результате ожидается, что темпы индексации МРОТ станут сопоставимы с темпами инфляции, благодаря чему в 2021 г. МРОТ вырастет на 5,5\%.

В соответствии с Постановлениями Конституционного суда РФ от 07.12.2017 № 38-П, от 28.06.2018 № 26-П, от 11.04.201 № 17-П, от 16.12.2019 № 40-П, в состав «заработной платы не ниже МРОТ» не включаются: «северные» районный коэффициент и процентная надбавка, выплаты за совмещение, сверхурочную работу, в ночное время, в выходные и праздничные дни. Перечисленные выплаты относятся к компенсационным.

Помимо этого, как полагает автор статьи, в состав «заработной платы не ниже МРОТ» не следует включать все выплаты стимулирующего характера, т. к. это противоречит самому их принципу, который предполагает поощрение и мотивирование персонала, а не доведение зарплаты до минимального уровня.

Определение «достойного уровня» оплаты труда в здравоохранении, само по себе, является сложной задачей.

Первым шагом в ее решении стал выбор конкретного ориентира, позволяющего рассчитать точное (цифровое) значение.

По мнению автора статьи, целевой показатель можно скорректировать, соотнеся его с уровнем зарплаты в ведущих промышленных предприятиях, производственные мощности которых расположены на территории региона (для которого производится расчет). 
Список таких предприятий по каждому субъекту РФ может быть сформирован на основе Перечня системообразующих организаций российской экономики, утвержденного Правительственной комиссией по повышению устойчивости развития российской экономики от 20.03.2020

№ 3 .

При предлагаемом подходе, уровень зарплаты врачей должен быть не ниже $100 \%$ среднего заработка работников этих предприятий с высшим образованием; уровень зарплаты среднего и младшего медперсонала - не ниже $100 \%$ и $80 \%$ среднего заработка работников со средним специальным образованием. (Уровень зарплаты медперсонала - средний заработок, рассчитанный на 1 ставку и без учета доходов руководящего состава).

Это может несколько усложнить предоставление и последующую обработку статистических данных, но, с учетом развития информационных технологий, только на начальном этапе.

\section{Заключение}

Сложносоставная структура заработной платы (основанная на применении двух различных перечней выплат) и высокая степень самостоятельности учреждений здравоохранения в распоряжении средствами приводят к манипуляциям с фондом оплаты труда и другим проблемам. Внешнее воздействие оказывают: жесткие законодательные требования к размеру заработной платы медицинского персонала, уровень финансирования учреждений.

Можно констатировать, что под задачей «стимулирования персонала», фактически, решались другие вопросы. Для того, чтобы механизм стимулирования реально заработал, прежде всего, нужно обеспечить конкурентоспособный базовый доход всем работникам, после чего создавать условия для поощрения лучших сотрудников. Это будет способствовать снижению социальной напряженности и повышению качества медицинской помощи, если во главу ставить именно этот приоритет, тогда как следование, исключительно, требованиям экономической эффективности приводит к дегуманизации здравоохранения [Rodin, 2015].

Федеральным законом от 09.11.2020 №362-Ф3 «О внесении изменений в Трудовой кодекс Российской Федерации» заложены основы для дальнейшего совершенствования системы оплаты труда в здравоохранении. Авторы законопроекта обещают, что при принятии решений будет проводиться оценка социальноэкономических, финансовых и иных последствий, что немаловажно.

\section{Список литературы}

1. Бутова В.Г., Олесов А.Е., Зуев М.В., Умарова К.В., Жеребцов А. Ю., Пешков В.А., 2017. Мониторинг компетентности медицинских работников стоматологических организаций в новой системе оплаты труда // Российский стоматологический журнал. 2017. № 21 (4): 211-216. DOI: 10.18821/1728-2802-201721-4-211-216

2. Госдума приняла в первом чтении проект о новой методике расчета МРОТ / Cетевое издание РИА Новости. [Электронный ресурс] Режим доступа: URL: https://ria.ru/20201111/mrot-1584101960.html (дата обращения: 15.11.2020).

3. Итоги федерального статистического наблюдения в сфере оплаты труда отдельных категорий работников социальной сферы и науки / Федеральная служба государственной статистики. [Электронный ресурс] Режим доступа: URL:

https://rosstat.gov.ru/storage/mediabank/ (дата обращения: 15.11.2020).

4. Лопатина М., Ляшок В., 2018. Исполнение майских указов 2012 г.: последствия для бюджетного сектора // Экономическое развитие России. 2018. № 9 (25): 89-94.

5.Медицина в регионах: итоги - 2019/ ООО «Газета «Новые известия». [Электронный ресурс] Режим доступа: URL: https://newizv.ru/article/tilda/10-12-2019/itogi2019-kakuyu-meditsinu-my-

poluchili\#rec147996859 (дата обращения: 15.11.2020).

6. О переводе младшего медицинского персонала на другие должности: Письмо Ми- 
нистерства Здравоохранения РФ от 7.02.2018 № 16-3/10/2-705 / АО «Кодекс». [Электронный pecypc] Режим доступа: URL: docs.cntd.ru/document/556638594 (дата обращения: 15.11.2020).

7. Подцероб, М., 2020. Врачи и медсестры переведены на новую систему оплаты / Cетевое издание «Ведомости». [Электронный ресурс] Режим доступа: URL: https://www.vedomosti.ru/management/articles/20 16/05/19/641522-vrachi-medsestri-perevedeninovuyu-sistemu-oplati (дата обращения: 15.11.2020).

8. Пояснительная записка к проекту федерального закона: Законопроект № 973252-7 / AO «Кодекс». [Электронный ресурс] Режим доступа:URL:

docs.cntd.ru/document/565109507 (дата обращения: 15.11.2020).

9. Проверки Роструда выявили факты невыплат врачам сверхурочных в регионах / Сетевое издание РИА Новости. [Электронный ресурс] Режим доступа: URL: https://ria.ru/20190820/1557718001.html (дата обращения: 15.11.2020).

10. Результаты исследования зарплаты врачей государственных медучреждений России / Сообщество «Врачи РФ». [Электронный ресурс] Режим доступа: URL: https://vrachirf.ru/company-announcesingle/40047 (дата обращения: 15.11.2020).

11. Семеко Г.В., 2010. Новая система оплаты труда в высшей школе - новые проблемы // Экономика образования. 2010. № 2: 69-77.

12. Синева О.В., 2018. Забайкальской больнице сокращают ставки из-за долгов / Деловой журнал «Vademecum». [Электронный ресурс] Режим доступа: URL: https://vademec.ru/news/2018/04/26/ (дата обращения: 15.11.2020).

13. Совместное заявление профсоюза «Действие» и Гильдии защиты медицинских работников о зарплатах медиков / Профсоюз медицинских работников «Действие». [Электронный ресурс] Режим доступа: URL: medrabotnik.org/news/v-srednem-v-rossii-vrachipoluchayut-na-6-1-tys-rub-menshe-ofitsialnyhdannyh (дата обращения: 15.11.2020).

14. Abuzyarova, D., Belousova, V., Krayushkina, Zh., Lonshcikova, Y., Nikiforova, E., Chichkanov, N., (2019), "The Role of Human Capital in Science, Technology and Innovation”,
Foresight and STI Governance, 13(2), 107-119. DOI: 10.17323/2500-2597.2019.2.107.119.

15. Rodin, L., (2015), "Governmentality" in the Clinical Context: The Paradoxes of Humanization of Healthcare in Sweden, The Journal of Social Policy Studies, 13(4): 643-656.

\section{References}

1. Abuzyarova, D., Belousova, V., Krayushkina, Zh., Lonshcikova, Y., Nikiforova, E., Chichkanov, N., (2019), "The Role of Human Capital in Science, Technology and Innovation", Foresight and STI Governance, 13(2): 107-119. DOI: 10.17323/2500-2597.2019.2.107.119.

2. Butova, V.G., Olesov, A.E., Zuev, M.V., Umarova, K.V., Zherebtsov, A.Yu., Peshkov, V.A., (2017), "The monitoring of dental organization's medical workers competences according to the new system of wage payments", Russian Journal of Dentistry, 21(4): 211-216. DOI: 10.18821/1728-2802-2017-21-4-211-216

3. The State Duma adopted in the first reading a draft on a new methodology for calculating the minimum wage / Setevoye izdanie RIA Novosti. URL: https://ria.ru/20201111/mrot1584101960.html (Accessed 15 November 2020).

4. Results of the federal statistical observation in the sphere of remuneration of certain categories of social workers and science / Federal State Statistics Service/ Federal'naya sluzhba gosudarstvennoy statistiki. URL: https://rosstat.gov.ru/storage/mediabank/ (Accessed 15 November 2020).

5. Lopatina, M. and Lyashok, V., (2018), "Implementation of the May 2012 decrees: consequences for the budgetary sphere", Russian Economic Development, 9 (25): 89-94.

6. Medicine in the regions: results of 2019 / OOO "Gazeta "Novyye izvestiya". URL: https://newizv.ru/article/tilda/10-12-2019/itogi2019-kakuyu-meditsinu-mypoluchili\#rec147996859 (Accessed 15 November 2020).

7. On the transfer of junior medical personnel to other positions: Letter from the Ministry of Health of the Russian Federation of 7.02.2018 № 16-3/10/2-705 / AO "Kodeks". URL: docs.cntd.ru/document/556638594 (Accessed 15 November 2020).

8. Podtserob M., (2016). Doctors and nurses in the new payment system / Setevoye izdaniye "Vedomosti".

URL: https://www.vedomosti.ru/management/articles/20 
$\underline{16 / 05 / 19 / 641522-v r a c h i-m e d s e s t r i-p e r e v e d e n i-~}$ novuyu-sistemu-oplati (Accessed 15 November 2020).

9. Explanatory Note to the draft Federal Law: Draft Law № 973252-7 / AO "Kodeks". URL: docs.cntd.ru/document/565109507 (Accessed 15 November 2020).

10. Rostrud inspections revealed the facts of non-payment of overtime to doctors in the regions / Setevoye izdaniye RIA Novosti. URL: https://ria.ru/20190820/1557718001.html (Accessed 15 November 2020).

11. Results of the study of salaries of doctors of state medical institutions of Russia / Soobshchestvo "Vrachi RF". URL: https://vrachirf.ru/company-announcesingle/40047 (Accessed 15 November 2020).

12. Semeko, G. V. (2010), "New system of remuneration of labor - new problems", Economics of education, 2: 69-77.

13. Sineva O.V., (2018). Zabaykalsky Hospital cut rates because of debts / Delovoy zhurnal "Vademecum".

URL:

https://vademec.ru/news/2018/04/26/ (Accessed 15 November 2020).
14.Joint statement of the Action Trade Union and the Guild of Protection of Medical workers on the salaries of doctors / Trade Union of Medical Workers"Action" / Profsoyuz meditsinskikhrabotnikov "Deystviye". URL: medrabotnik.org/news/v-srednem-v-rossii-vrachipoluchayut-na-6-1-tys-rub-menshe-ofitsialnyhdannyh (Accessed 15 November 2020).

15. Rodin, L., (2015), "Governmentality" in the Clinical Context: The Paradoxes of Humanization of Healthcare in Sweden, The Journal of Social Policy Studies, 13(4): 643-656.

\section{Информация о конфликте интересов:} авторы не имеют конфликта интересов для декларации.

Conflicts of Interest: the author has no conflict of interest to declare.

Соболева Е. А., научный исследователь, ФГБОУ ВО «Байкальский государственный университет» (Иркутск, Россия)

Soboleva E.A., Scientific Researcher, Baikal State University, Irkutsk, Russia 